instead of less in wages after the rise in oil prices from 1973. The professional associations to which so many of the group belong did just the same! In any case, though there is some truth in the analysis it is over-simple. So, incidentally, is the remark that 'Pentecost has come again in the unlikely guise of TV'. To disentangle the truth from the error contained in it is but one instance of the stimulus to thought which the whole report provides.

PROFESSOR RONALD PRESTON

Faculty of Theology

Manchester University

\section{Psychiatric Ethics}

Eds Sidney Bloch and Paul Chodoff, Oxford University Press, Oxford £I2.50

This volume is a welcome contribution to the literature on psychiatric ethics, with papers from historical, sociological, legal and philosophical perspectives. Papers are on diagnosis, research, training in ethics, the abuse of psychiatry in the Soviet Union and suicide. There are several on particular treatments (drug therapy, sex therapy, psychotherapy and psychosurgery) and on specialties (child and forensic psychiatry). The contributors are mainly distinguished psychiatrists from the United States and England.

In their introduction the editors note that recent concern in psychiatric ethics has arisen for a variety of reasons, including the critiques of Laing and of Szasz, as well as from an awareness of the actual and potential political abuse of psychiatry. They suggest several ways in which psychiatry raises ethical issues additional to those in medical practice generally, including the deprivation of freedom for reasons of mental illness, the increased likelihood of conflict between individual and social responsibilities, and the controversial status of 'mental illness' and its diagnosis. They have organised a wide range of material in a helpful way, with repetition - difficult to avoid in a collection of this sort - kept to a tolerably low level. On the whole, the papers are excellently written and include comprehensive bibliographies.

On the other hand, it should be said that one of the main strengths of the volume is also something of a weakness. Most of the papers are by distinguished members of the psychiatric establishment, which certainly brings the benefit of authoritative and informed discussion. However, it also means that some of the pressing issues are dealt with, if not complacently, at least with little or no serious questioning of conventional psychiatric practice in America and England. Radical criticisms and proposals by psychiatrists, lawyers and others, while mentioned for the purpose of discussion, have no direct representation in the volume. Their inclusion would have served to balance the rather conservative, though by all means reasonable, views of the majority of the contributors. Connected with the general acceptance of current practice is an implicit assumption that the individual psychiatrist's conscience conforms with the demands of his professional role.

While the volume contains much discussion of ethical aspects of the relationship between psychiatrist and patient (such as informed consent), and of that between psychiatrist and third parties (such as confidentiality), there is very little examination of ethical difficulties which may arise for the individual psychiatrist in relation to the professional and institutional setting within which he works, and by which his freedom of action is implicitly and explicitly constrained. However, such shortcomings do not detract from the substantial positive achievements of the volume, which the reviewer recommends without hesitation to those involved with ethical issues in psychiatry, which includes all practising psychiatrists, and particularly to those responsible for training.

\section{DEREK BOLTON The Bethlem Royal Hospital Beckenham Kent \\ A Philosophical Basis of Medical Practice}

\section{Edmund Pellegrino and David Thomasma Oxford University Press, New York £ I I.50}

Philosophers have not, until recent times, been welcomed, much less invited to provide their conceptual and critical skills as a service to the State or to established and successful professions such as those in the area of the sciences. We need only remind ourselves of the fate of Socrates to realise that the skills of the philosopher have been judged at best as confusing and, at worst, as socially disruptive and dangerous. The philosopher is accused of having no content of his own to reflect on and viewed, therefore, as parasitic on the content of alternative disciplines for reflection. A Philosophical Basis of Medical Practice exhibits a constructive change from this traditional stereotype of the philosopher in the ever-expanding dialogue with medicine. The exchange is seen to be mutually beneficial, a welcome advance over the outmoded model of the wise philosopher unilaterally offering his insights into the meaning and purpose of human existence. Philosophy gains in the mutual exchange by gaining access to concrete, verifiable and measurable data about human life as ground for reflection and inquiry while, at the same time, medicine is urged to overcome its anti-philosophical bias and its own claims to preciosity and sacerdotal privilege. The two authors, Pellegrino and Thomasma, have brought their own expertise from medicine and philosophy to articulate the features of a philosophy of medicine and its applicability to both individual and social ethics.

What is most ambitious and impressive about the book is the attempt to provide a comprehensive conceptual framework of ontology, method and value theory within which the interfaces between philosophy and medicine cam be more clearly and systematically? spelled out. The framework includes a delineation of a philosophical method to be pursued; reflection on the nature of medicine; an ontology of the body, and the anatomy of clinical judgments. A fundamental claim which is argued for throughout, and which is essential to establishing the links between philosophy and medicine, is that medicine is clearly not a value-free science. Insofar as many of the assumed factual judgments of medicine are either valueladen themselves or reveal value presuppositions, these judgments invite critical scrutiny from the philosopher. Value-laden judgments which pervade the practice of medicine are not construed as suspect in an a priori manner but are made explicit in the interest of achieving greater understanding of the foundations of medical practice.

The clinical situation is analysed as a calculus of interacting variables all governed by, geared to, and reflecting the patient's need. Predictably, the patient-physician relationship comes under detailed philosophical scrutiny, a scrutiny which rejects the Hippocratic image of the physician as a paternalistic, albeit benevolent, authority in both technical and moral matters. The analysis of the nature of medicine and 
the doctor-patient relationship does not pretend to be the final word. Specifically, the social character of medicine is in the process of profound alteration and a challenge is posed for some rational controls, some judicious containment of expanding medical influence. A chapter on 'Discretionary Space in Professional Judgment' examines the degree of latitude in decision-making that society accords its medical experts while specifying the forces that tend to narrow that latitude today. Consistent with the method of the entire book, the authors provide an historical discussion on the origins of society's queries into the limits of latitude in medical decision-making.

This study is an earnest attempt to engage the interest of healthprofessionals, philosophers and sociologists alike. While some of the language used may be unnecessarily cumbersome and technical, overall the project steers a middle-course in striving for accuracy of clinical input and clarification of philosophical concepts which are often left too obscure for the non-professional.

DOLORES DOOLEY-CLARKE Department of Philosophy University College Cork, Ireland

\section{Mental Illness: Law and Public Policy}

\author{
Eds Baruch A Brody and $\mathrm{H}$ Tristram \\ Engelhardt Jr \\ D Reidel Publishing Company, Dor- \\ drecht, Holland 1980. \\ $\$ 28.95$
}

This is of the nature of a symposium on the rationale governing the relation in which the law stands vis-à-vis the mentally sick as contrasted with the normal person. The use, or misuse, of the word 'normal' incidentally directs attention to one of the main basic problems. The professional qualifications of the respective contributors are interesting eight philosophers, two doctors of medicine and two lawyers. Inevitably this has led to a certain amount of repetition in some of the papers. On the other hand, if the basic concepts which do, or should, influence the relation are to be seriously examined this is best done by philosophers. The book is of the greater interest to lawyers and doctors because of its study of the problem by members of other than their own specialties. It thus avoids the substitution of arid technicalities for the examination of principles.
The weakness in the dichotomy nor$\mathrm{mal} / \mathrm{insane}$ is one which is apparent to the psychiatrist, accepted willingly by the philosopher, and admitted, but reluctantly and only recently, by the lawyer. The criminal lawyer is largely concerned with 'responsibility' - a better word is 'answerability'. The judicial introduction in Scotland in I865 of the status 'diminished responsibility' was strongly criticised by some other judges, on the ground that a man or woman was either responsible or was not. That criticism, namely that normalcy is not a matter of degree, is not now heard, although the decreased utility of the plea, since death has ceased to be the mandatory punishment for murder, may revive logical objections to it.

Much of the symposium is, naturally, taken up with criticisms of the McNaghten Rules, and of the attempts, such as those of Rae and Doe, to formulate law more consonant with what is now known about mental illness. One aspect of the problem was not, I think, considered. It would not be profitable to devise a formula which is intellectually and scientifically satisfactory only to psychiatrists, academic lawyers, and even judges. The rule must be capable of being intelligibly explained to the ordinary men and women who constitute the jury, because theirs is the decision. The point was well made by a very distinguished judge in his evidence before the Royal Commission on Capital Punishment (I 953): 'However much you charge a jury as to the $\mathrm{McNaghten}$ Rules or any other test, the question they would put to themselves when they retire is - "Is this man mad or is he not?".' Probably it is not worthwhile looking for a just criterion unless you are prepared to remove this part of the decision from the province of the jury.

Legal maxims may outlive any virtue they once had. At least two of the essayists, in their treatment of involuntary civil commitment, quote the old saying 'Better that 99 guilty men escape than that one innocent man be convicted' (or some other proportion), and ask why the same anxiety is not shown in admissions to mental hospitals. Others give rational answers, but there may be a deeper, though perhaps unpalatable, consideration. The saying was undoubtedly true when all felons might be sentenced to death. But is it sound today? Or perhaps we are just not allowed to doubt it. An even more questionable proposition, the 'presumption of innocence', has now been enshrined in the various declarations of human rights, and so is protected from discussion.

I don't know whether this book is more valuable for its sheer expertise or for making the reader take out his own ideas, look at them, and think hard.

LORD KILBRANDON

former Lord of Appeal

Oban, Argyll

\section{Under the Doctor}

\section{Standford Bourne}

Avebury Publishing Co: Gregg International, Amersham, Bucks

$\boldsymbol{f}_{\text {I } 2.00 \text { hardback, } £_{5} .95 \text { paperback }}$

This is an important and interesting book. It is an account of a study based on a two-year seminar with a group of physiotherapists. The leader is a psychoanalyst, and the theoretical underpinning is psychoanalytic. However, concepts are used economically, are explained in simple language, and are carefully linked to what happens in real situations. The book is divided into two parts: part one is a synthesis based on observations from the sessions; part two contains the 'primary data' of the sessions themselves, as recorded by the seminar leader.

The result is a lucid account of the complex tangle of feelings and problems which surround and impinge upon the patients and their families as they interact with a group of professionals, and of the inter-professional tensions. Much contemporary medical care involves, increasingly, 'teams', whose members have different skills and roles and who, supposedly, work together. However, many problems are often not thought out. The resulting stresses affect, in different ways, the various members of the team, and, of course the patient. Problems are particularly difficult in chronic, severe, or 'hopeless' cases.

Though based on the particular professional roles of the physiotherapist, and taking up such issues as the feminine professional image; the conflicts involved in relating in a 'talking' and a 'physical' way; the relationships between the physiotherapist and her colleagues, and professional isolation, the book contains much that will interest all concerned with patient care, both in hospital and in the community, from consultant to student. It deserves to be widely read, studied and discussed.

C J LUCAS 7 I Ravensdale Avenue London 